\title{
Starting a Company When You Have a Day Job
}

\section{Todd Connor (Bunker Labs)}

Daniel Forbes (University of Minnesota, Carlson School of Management)

KEYWORDS: Entrepreneurship, financing.

You're gainfully employed with a steady paycheck, but you have a great idea for your own company. Should you quit your job to launch your venture?

In this interview with EIX, "Third Shift Entrepreneur" (https://www.amazon.com/Third-Shift-Entrepreneur-

Build-Dream/dp/1119708362) author Todd Connor provides wise advice about making the leap without jeopardizing your financial future. Connor has played many roles in life: Navy officer, management consultant, entrepreneur and author. However, a common theme of his experiences has been finding ways to help people of all ages to reach their potential. For example, the organization he founded, Bunker Labs (https://bunkerlabs.org), helps veterans start and grow their businesses and now has chapters across the U.S. And as Executive Director of Military Schools for Chicago Public Schools, Todd led JROTC programs for 11,000 high school students. More recently, Todd has founded a new organization, the Collective Academy, that provides career and leadership development programs for individuals and organizations.

He counsels future entrepreneurs to leave full time work only when it's riskier to stay there than to be on their own. "It's about keeping an eye on tomorrow, without creating a financial liability," he says.

Check out the video for more advice. Says Connor: "You are really closer than you think to starting something." 